\title{
HEMODYNAMIC MONITORING USING THORACIC BIOIMPEDANCE - AN OPTIMAL SOLUTION FOR THE TREATMENT OF HYPERTENSION
}

\author{
ANCA DANIELA FARCAS, FLORIN PETRU ANTON, MIHAELA MOCAN, \\ LUMINITA ANIMARIE VIDA-SIMITI
}

\author{
Internal Medicine Department, Iuliu Hatieganu University of Medicine and \\ Pharmacy Cluj-Napoca, Romania \\ Internal Medicine Department, Emergency County Clinical Hospital Cluj- \\ Napoca, Romania
}

\begin{abstract}
Hypertension is a major issue of public health because of its increasing prevalence and multiple complications caused by failing to achieve an efficient blood pressure control. Considering hypertension as a hemodynamic disorder allows to prescribe a tailored therapy guided by individual hemodynamic parameters, therefore leading to an increased rate of control. We present the case of a 59 years old diabetic, dyslipidemic and obese male who, although treated with 5 classes of antihypertensive drugs had uncontrolled hypertension that caused left ventricular failure. Using the HOTMAN system of hemodynamic monitoring using thoracic electrical bioimpedance allowed a quick identification of the cause and guided the therapy, achieving blood pressure control after 5 days of treatment. Treating hypertension by identifying the underlying hemodynamic imbalance allows prescribing a tailored therapy and shortens the initiation and stabilization phases of treatment.
\end{abstract}

Keywords: hypertension, hemodynamic, treatment, bio-impedance, antihypertensive treatment

Hypertension is a significant and well-known risk factor for cardiovascular diseases, associated with high mortality. In Romania the prevalence of hypertension is $45.1 \%$ and on the rise in the last 7 years, possibly caused by increased incidence of risk factors such as unhealthy diet, obesity, diabetes or dyslipidemia [1].

Although $72.2 \%$ of patients receive treatment [2] and although $51.9 \%$ of them receive 2 or 3 medications, only $30.8 \%$ reach blood pressure (BP) goals [1], thus making hypertension in Romania an "unsolved equation" [2].

In spite of major advances in treatment and efforts to follow the guidelines, a significant number of patients are still poorly controlled even in other European countries [3].

This might be caused by the current paradigm that views hypertension merely as a BP disorder and not as a hemodynamic imbalance. Published data suggest that prescribing antihypertensive therapy guided by hemodynamic parameters gathered using thoracic electrical bioimpedance would increase the $\mathrm{BP}$ control rate $[4,5]$.

Manuscript received: 23.06.2018

Received in revised form: 06.07.2018

Accepted: 23.07.2018

Address for correspondence: florinantonfr@yahoo.com
The HOTMAN system (HEMO SAPIENS, INC). uses thoracic electrical bioimpedance to identify hemodynamic imbalances in hypertensive patients, thus allowing the physician to choose optimal therapy and appropriate dosage for each patient [6].

\section{Case report}

A 59-year-old male with very high-risk stage 3 hypertension, type 2 diabetes with diabetic chronic kidney disease (CKD) and neuropathy, dyslipidemia and obesity is referred for edema, resting dyspnea and nocturnal paroxysmal dyspnea in the last 2 weeks. The patient has difficult BP control with repeated peaks reaching 180/100 mmHg. Clinical examination shows a patient with abdominal obesity, edema, pulmonary rales, BP 160/100 $\mathrm{mmHg}$, pulse $65 \mathrm{bpm}$ and no heart murmurs. Current medication includes valsartan $160 \mathrm{mg}$ bid, lercanidipin $10 \mathrm{mg}$ od, moxonidine $0.4 \mathrm{mg}$ od, indapamide $1.5 \mathrm{mg}$ od and nebivolol $5 \mathrm{mg}$ od. Laboratory workup shows fasting plasma glucose $124 \mathrm{mg} / \mathrm{dl}, \mathrm{HbA} 1 \mathrm{c} 7.1 \%$, LDL-cholesterol $69 \mathrm{mg} / \mathrm{dl}$, HDL-cholesterol $55 \mathrm{mg} / \mathrm{dl}$, triglycerides 178 $\mathrm{mg} / \mathrm{dl}$, creatinine $1.1 \mathrm{mg} / \mathrm{dl}$, creatinine clearance $72.8 \mathrm{ml} /$ 
$\min / 1.73 \mathrm{~m}^{2}$, microalbuminuria $-189 \mathrm{mg} / \mathrm{dl}$ and potassium $4.3 \mathrm{mEq} / \mathrm{l}$. Echocardiogram shows mild concentric left ventricular (LV) hypertrophy (LV posterior wall thickness $12 \mathrm{~mm}$, interventricular septal thickness $12 \mathrm{~mm}$ ), grade I mitral regurgitation and grade I diastolic dysfunction. The patient's diagnosis is very high-risk grade 3 hypertension, hypertensive and ischemic heart disease, grade I mitral regurgitation and acute LV failure. In order to control LV failure symptoms and prevent further complications, tight $\mathrm{BP}$ control is required - BP needs to be brought below 130/80 mmHg.

For a patient with diabetic CKD and hypertension under treatment with 5 types of antihypertensive drugs (angiotensin receptor blocker, calcium antagonist, indapamide, beta-blocker and a centrally acting agent) what other medication could be added? The European hypertension guidelines suggests adding an alpha-receptor blocker.

Another answer to this question could be provided by the HOTMAN F100 system (HEMO SAPIENS, INC). The system uses the thoracic electrical bioimpedance to gather hemodynamic data on volemia, vasoactivity, inotropy and chronotropy that are specific to each hypertensive patient.

Using these parameters the device allows a virtual modeling of therapy and provides information on the impact of changes in therapy. For this patient, HOTMAN monitoring shows a status with $86 \%$ hypervolemia and no vasoconstriction (Figure 1).

"Virtual therapy" shows that adding a vasodilator would achieve a $40 \%$ hyperdinamic/normotensive status with $83 \%$ hypervolemia and 30\% hyperchronotropy, as shown in Figure 2.

Achieving the BP goal therefore requires the addition of a diuretic, as shown in "virtual therapy" (Figure 3).

The patient's treatment already includes indapamide - a thiazide diuretic which has both vasodilator and diuretic effects, therefore it is continued - thus a combination of loop diuretic (Furosemide) and kalium-sparing diuretic (Spironolactone) is added, in order to reduce the hypervolemia by a combined diuretic effect and also to avoid hypokalemia.

After five days of treatment with the new regimen the patient is asymptomatic, BP is normal $(110 / 70 \mathrm{mmHg})$ and HOTMAN monitoring shows a normodynamic/ normotensive status with only $37 \%$ hypervolemia (Figure 4).

HOTMAN monitoring after 20 days of treatment with Valsartan $160 \mathrm{mg}$ bid, Lercanidipine $10 \mathrm{mg}$ od, Moxonidine $0.4 \mathrm{mg}$ od, Indapamide $1.5 \mathrm{mg}$ od, Nebivolol $5 \mathrm{mg}$ od, Furosemide $40 \mathrm{mg}$ od and Spironolactone $50 \mathrm{mg}$ od shows a normotensive/normodynamic status with $40 \%$ hypervolemia (Figure 5).

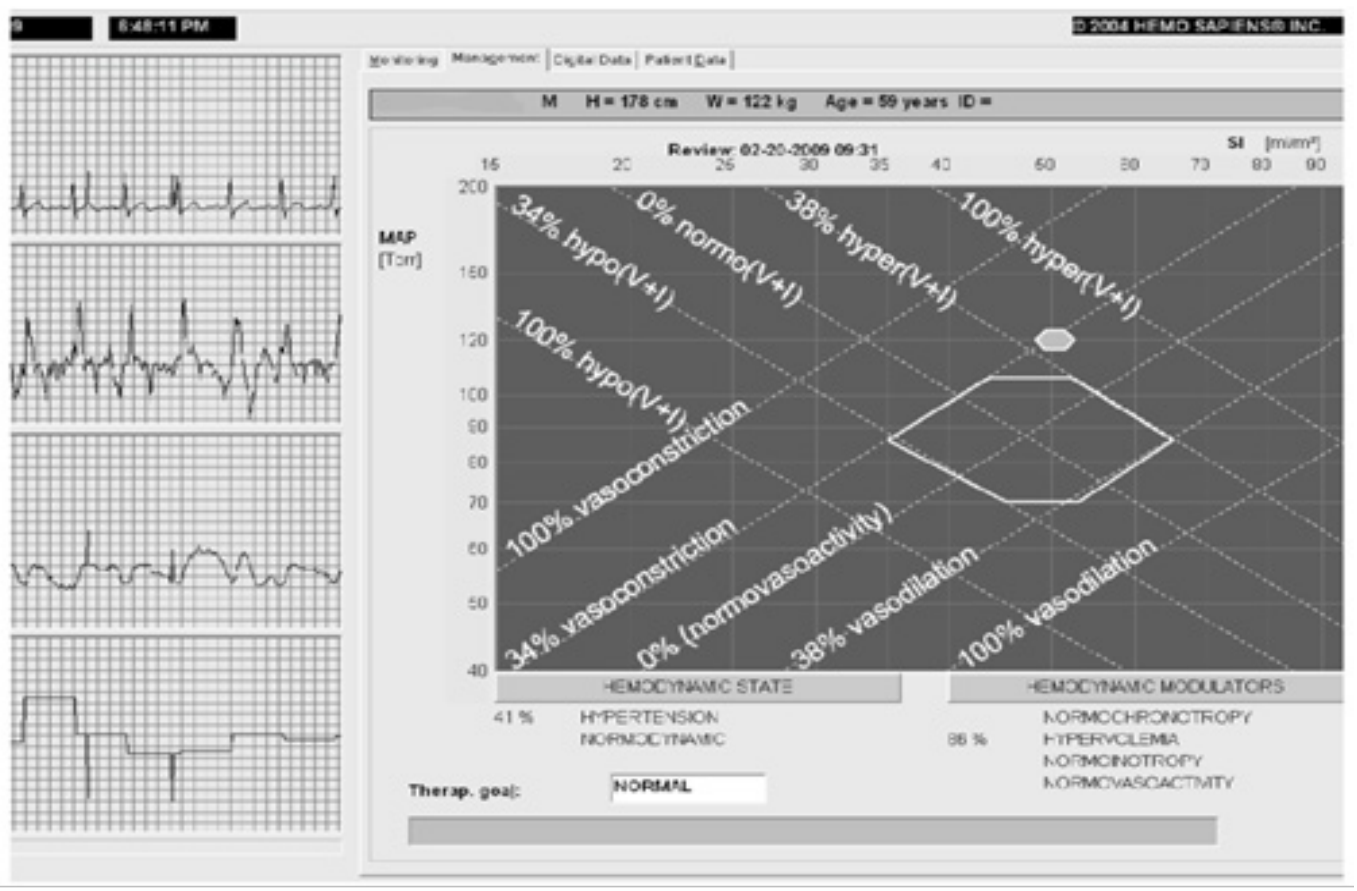

Figure 1. Hemodynamic status at first evaluation. 


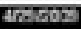

FRTाPप

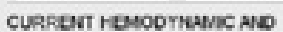
CHAONOTROPIC STATE IS EXPRESSED AS A CENTER POSITION ON ALL FOUR MCDULATOR SLIDEAS. USR MOUSE TO DRAO

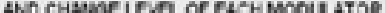
ANO WATCH BOTH TIE VECTORLL EFTECTS ONI HEMCONIEMIC STATE AND ON

CHePONOTROPY.

\section{Volume}

SELECTED THERAPY

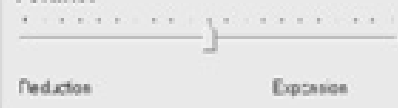

Inotropes

$\frac{+\ldots \ldots+\cdots}{\text { Neostive }}$

Vasoact. drugs

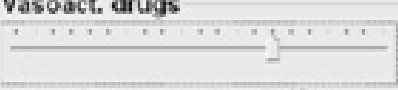

Vwioconutioton Volodvactem

\section{Chronotropes}

$\frac{\ldots \ldots+\ldots}{\text { Negates }}$

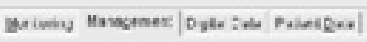

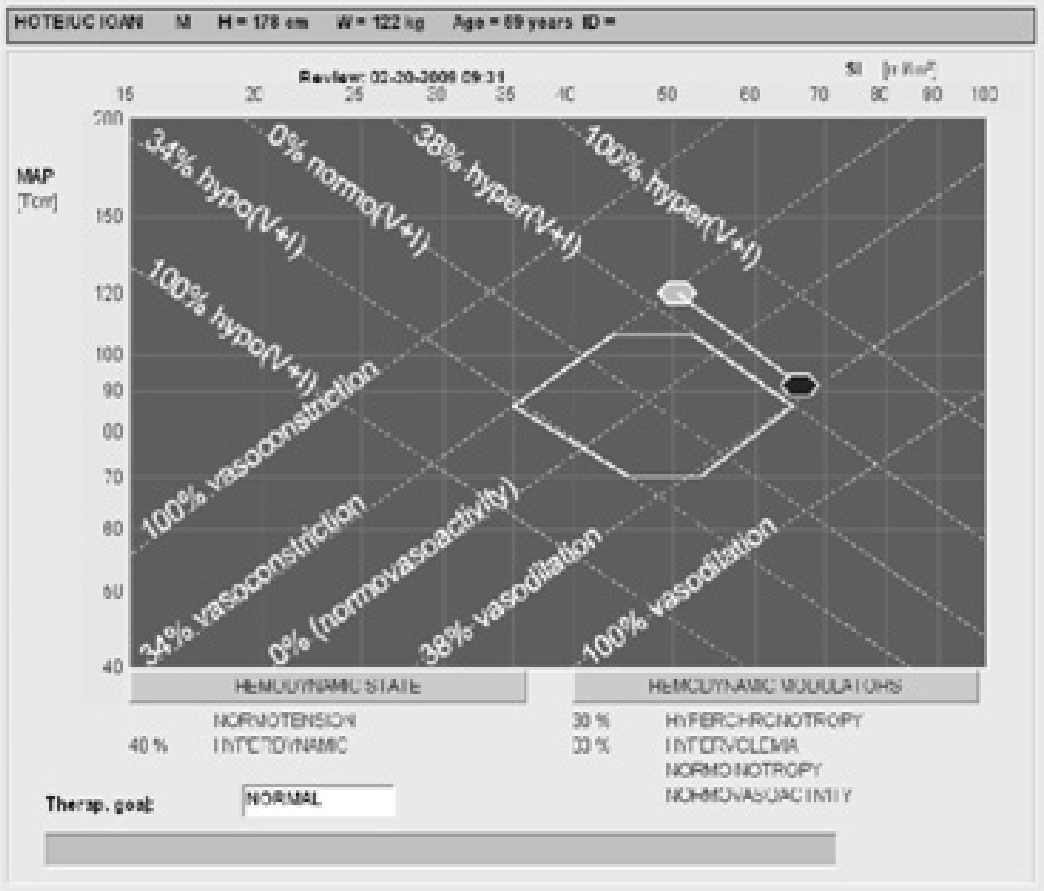

Figure 2. Worsened hemodynamic status after adding a vasodilatator.

\section{[C.TW2}

[E] PM

CURPEVT HEMOOYNULAC ANO

CAROLOTROFIC STATE IS EXPRESSED AS A

CENTER POSITION ON ALL FOUR

MOOUMTCR SLDERS. USE MCUSE TO DRAO

HWD CHAVEE LEVEL OF EACH MOOULTCR

AOD WATCH BOTH THE VECTOPIS EFFECTS

ONHEMCOVMASIC STATE AND ON

CHRONOTROPY.

\section{SELCTEO THFALP}

Volume

Pasacion

\section{Inotropes}

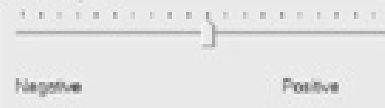

\section{Vasoact. drugs}

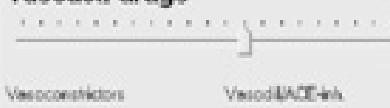

\section{Chronotropes}

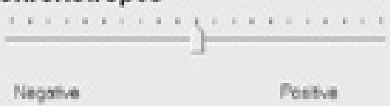

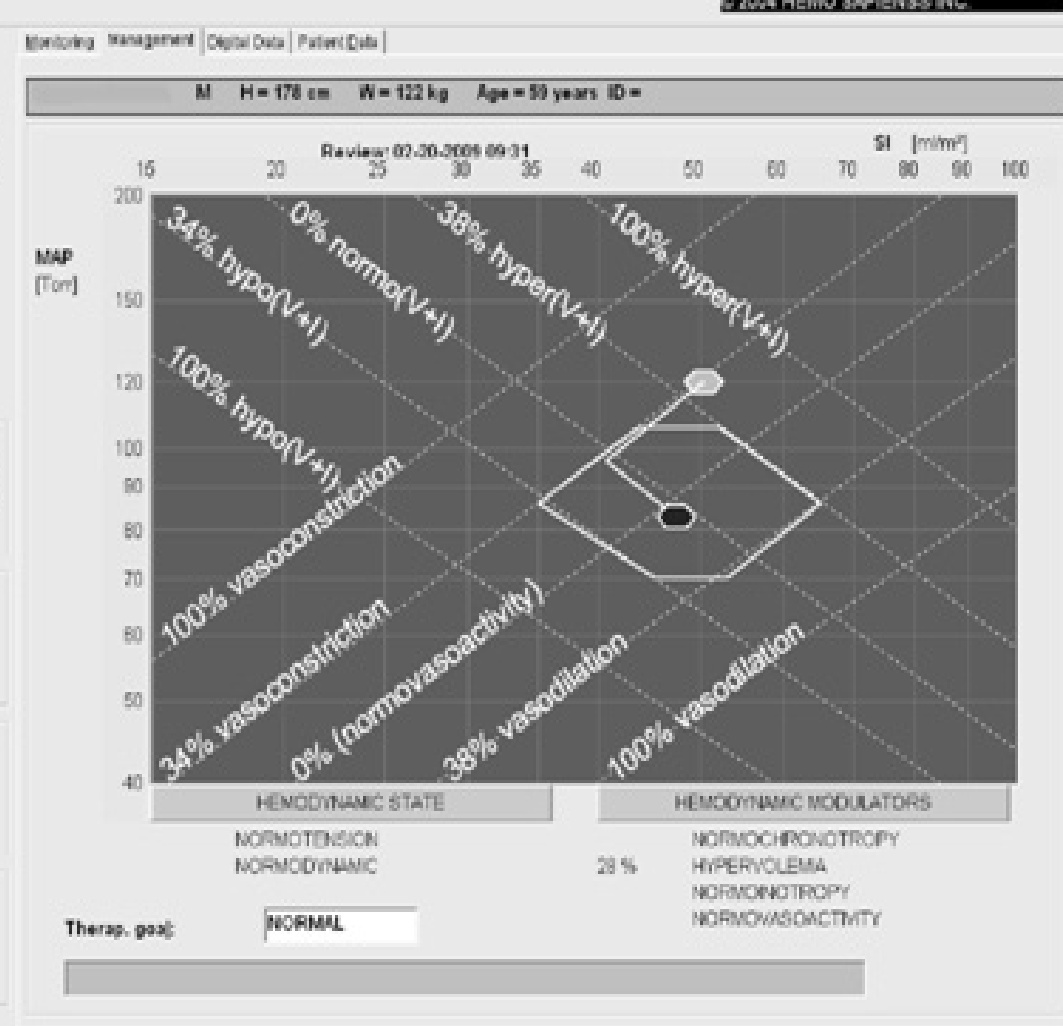

Figure 3. Improved hemodynamic status after adding a diuretic 


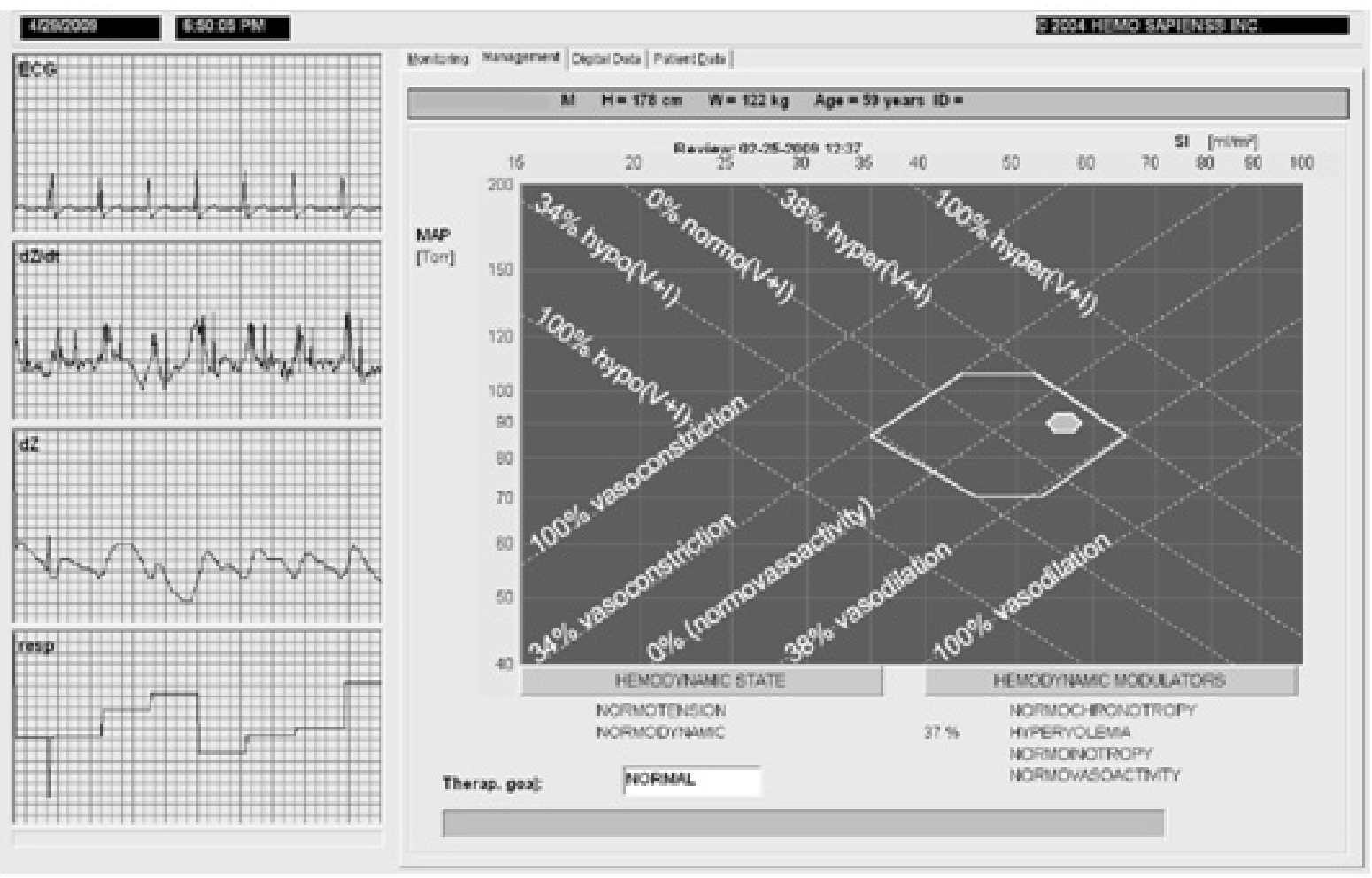

Figure 4. Hemodynamic status after 5 days of new treatment.

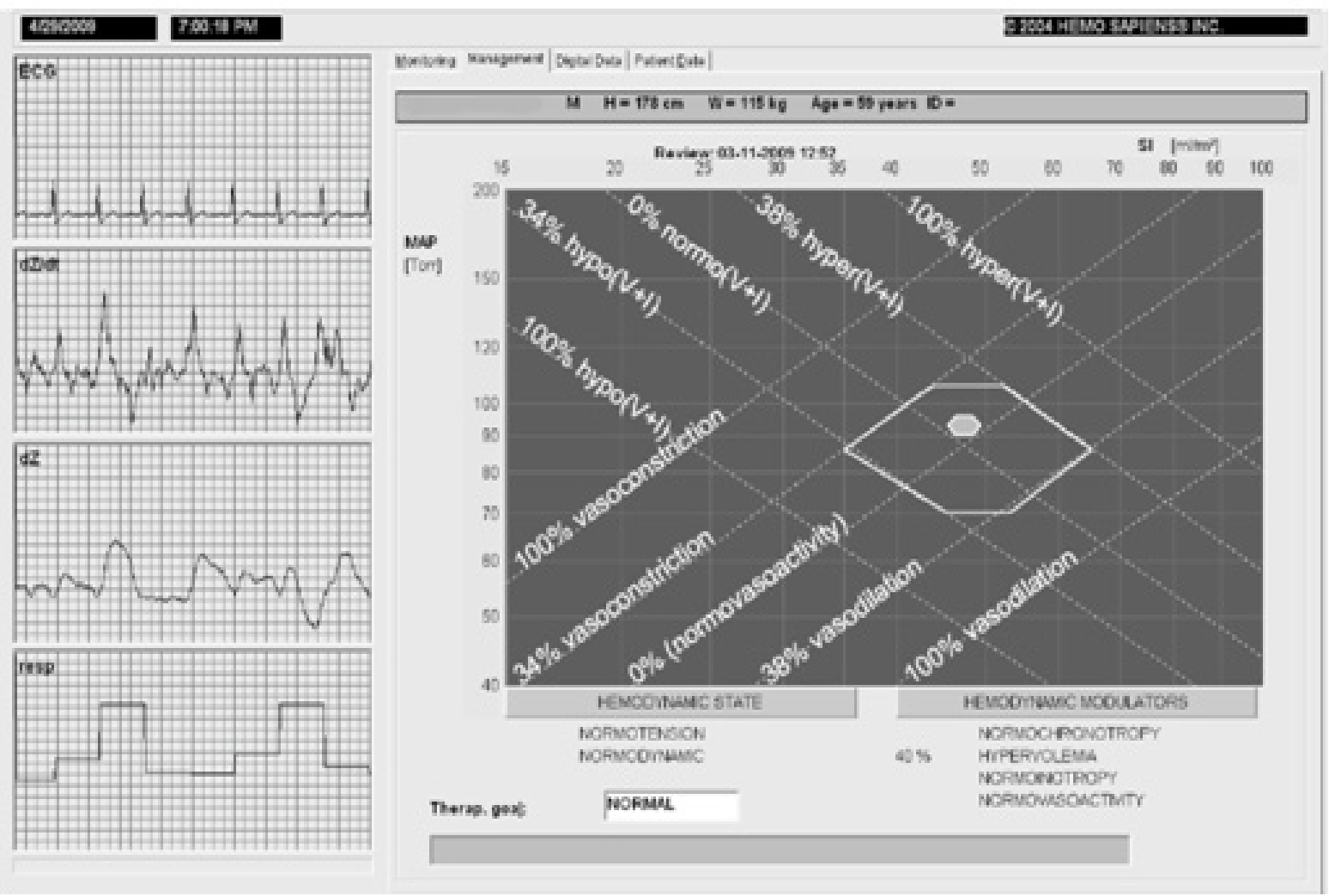

Figure 5. A normotensive/normodynamic status after 20 days of new treatment. 


\section{Discussion}

We present the case of a patient treated with 5 classes of antihypertensive drugs that failed to reach BP goal and who had cardiac dysfunction due to organ damage - a widespread scenario found in daily practice. Using a trial-and-error approach to therapy would not bring any benefits and would actually prolong or even worsen the current status of the patient, whereas using the HOTMAN monitoring allowed a quick and accurate identification of the optimal type of medication needed and achieving better BP control. Besides, using noninvasive hemodynamic monitoring in BP control was proven to be extremely useful $[7,8]$, both in newly diagnosed patients and longtime but uncontrolled hypertension [9,10], and ultimately improved the outcome for hypertensive patients [11]. A meta-analysis of 7 studies enrolling 1087 patients has shown that prescribing medication using hemodynamic monitoring protocols leads to an average control rate of $72.6 \%$ [7]. The study of Sramek et al. achieved BP control in $75 \%$ of patients already treated with 2 or more drugs, after only 3 weeks of treatment [12].

\section{Conclusion}

Hemodynamic monitoring in hypertension with thoracic electrical bioimpedance using the HOTMAN ${ }^{\mathrm{TM}}$ F100 system (HEMO SAPIENS, INC.) provides valuable data for hypertension treatment. Following the system's recommendations leads to an expedited stabilization of the patients' status, therefore shortening the initiation and stabilization phases of the treatment, which can often be a frustrating period, both for the physician and for the patient.

\section{References}

1. Dorobantu M, Tautu OF, Dimulescu D, Sinescu C, GusbethTatomir P, Arsenescu-Georgescu C, et al. Perspectives on hypertension's prevalence, treatment and control in a high cardiovascular risk East European country: data from the SEPHAR III survey. J Hypertens. 2018;36(3):690-700.

2. Dorobanţu M, Darabont R, Ghiorghe S, Arsenescu-Georgescu
C, Macarie C, Mitu F, et al. Hypertension prevalence and control in Romania at a seven-year interval. Comparison of SEPHARI and II surveys. J Hypertens. 2014;32(1):39-47.

3. Banegas JR, López-García E, Dallongeville J, Guallar E, Halcox JP, Borghi C, et al. Achievement of treatment goals for primary prevention of cardiovascular disease in clinical practice across Europe: the EURIKA study. Eur Heart J. 2011;32(17):2143-2152.

4. Chacón-Lozsán F. Non-Invasive Hemodynamic Analyses to Guide Pharmacotherapy of High Blood Pressure: Mini-Review. Journal of Cardiology \& Cardiovascular Therapy 2017;3(3):1-3.

5. Krzesiński P, Gielerak G, Stańczyk A, Piotrowicz K, Skrobowski A. Who benefits more from hemodynamically guided hypotensive therapy? The experience from two randomized, prospective and controlled trials. Ther Adv Cardiovasc Dis. 2016;10(1):21-29.

6. Farcas AD, Stoia MA, Anton FP, Goidescu CM, Vida-Simiti L. Improving blood pressure control beyond the guidelines. European heart journal. 2016;37:212-213.

7. Chacón-Lozsán F, Rodriques-Torres M, Rojas R. Hemodynamic Management of High Blood Pressure. Therapeutic Advances in Cardiology. 2017;1(3):73-79.

8. Viigimaa M, Talvik A, Wojciechowska W, Kawecka-Jaszcz $\mathrm{K}$, Toft I, Stergiou GS, et al. Identification of the hemodynamic modulators and hemodynamic status in uncontrolled hypertensive patients. Blood Press. 2013;22(6):362-370.

9. Hernández-Hernández R, Domenech M, Coca A. 481 Hemodynamic evaluation and selection of hypertension treatment. Journal of Hypertension. 2012;30:e142-e143.

10. Krzesiński P, Gielerak GG, Kowal JJ. A "patient-tailored" treatment of hypertension with use of impedance cardiography: a randomized, prospective and controlled trial. Med Sci Monit. 2013;19:242-250.

11. Sramek BB, Badila E, Bartos D, Tîrziu C, Ghiorge S. Treating hypertension as a hemodynamic disorder results in three-fold improvement in outcomes. American Society of Hypertension - 23rd Annual Scientific Meeting and Exposition, 2008. Abstract Number: 350091. Available from: http://www. hemodynamicsociety.org/ash2008.html

12. Sramek BB, Ticky JA, Hojerova M, Cervenka V. Normohemodynamic goal-oriented antihypertensive therapy improves the outcome. The American Society of Hypertension, 11th Scientific Meeting, New York. 1996. Available from: http:// www.hemodynamicsociety.org/abstract.html 